\title{
O QUE FALTOU NA TORRENTINA: O PERÍOdO PADUANO DA VIDA DE ANDREA MANTEGNA
}

Nancy Kaplan

Há quinhentos anos, na noite de 13 de setembro de 1506, morria em Mântua Andrea Mantegna (1430/31-1506). Contava cerca de 76 anos e encontrava-se gravemente enfermo há bastante tempo. Por mais de quatro décadas, ele fora o pintor da corte dos Gonzaga e muito contribuíra para torná-la o centro humanista almejado por Ludovico III quando, no fim dos anos cinqüenta, convidara-o a deixar Pádua para instalar-se em Mântua. Mantegna foi sepultado com honras na capela familiar de São João Baptista em Sant'Andrea, a imponente igreja projetada por Alberti (1404-72). Foi um final digno para a vida do homem que nas palavras de Vasari "nasceu de humilíssima estirpe, filho de carpinteiro, e na infância apascentava o gado".

No texto fundador da História da arte italiana, As Vidas dos mais excelentes pintores, escultores e arquitetos, Giorgio Vasari retoma o modelo das biografias de homens ilustres da Antiguidade, relatando as vidas dos artistas italianos desde Cimabue até Michelangelo.

A vida de Mantegna é apresentada por Vasari com diferenças significativas nas duas edições das Vidas. Em 1550, na Torrentina, Vasari cita, breve e erroneamente, o período paduano de Mantegna. Já em 1568, na edição Giuntina, ele se estende na descrição das primeiras obras e nas conflituosas relações do pintor com Squarcione (1397-1468).

Entre a redação de ambas, Vasari teve acesso a uma carta escrita em latim por Girolamo Campagnola (c.1433/5-1522) a respeito dos antigos pintores de Pádua. O notário Campagnola, contemporâneo e amigo de Mantegna, é recordado pelas fontes mais antigas, Scardeone e Michiel, como literato e poeta. Freqüentava os círculos humanistas paduanos e, segundo Vasari, era ele próprio um artista e teria estudado com Squarcione. O filho Giulio (c.1482-1514) destacou-se como gravador e trabalhou com Mantegna.

A carta de Campagnola, hoje perdida, era muito famosa na época de Vasari e também foi utilizada como fonte por Marcantonio Michiel. O destinatário era Niccolò Leonico Tomeo, veneziano de origem albanesa, que fora aluno de Domenico Calcondila em Florença e era então tradutor de obras científicas e professor de literatura grega na Universidade de Pádua.

No século XV na Itália setentrional, somente Pádua podia se equiparar a Florença como um centro de cultura. Isso se deve em muito à tradição universitária da cidade, cuja Universidade foi fundada em 1222. Formou-se ao longo dos anos ao redor dos mestres e de seus alunos, um círculo de intelectuais, não necessariamente vinculados à Universidade, devotado ao estudo da Antiguidade. A atividade artística encontrava correspondência e apoio no meio intelectual.

A vida artística mostrava-se tão rica e estimulante quanto a intelectual. $\mathrm{Na}$ capela da Arena, encontravam-se os afrescos de Giotto (c.1266-1337) e na igreja do Santo, os de Veronese Altichiero (c.1369-1469). Por volta de 1443, Fra Filippo Lippi (c.1406-1469) e 
Paolo Uccello (c.1396-1475) acompanharam Donatello (c.1386-1466) a Pádua, pintando afrescos na igreja do Santo e na capela do Podestà.

Foi a esse estimulante ambiente cultural que Andrea Mantegna chegou por volta dos dez anos de idade, vindo da pequena Isola di Carturo para ser aprendiz no ateliê de Squarcione.

Francesco Squarcione é uma figura nebulosa e intrigante e o seu papel na formação de Mantegna é discutível. Do pouco que se sabe, é certo que fosse alfaiate e bordador. Nascido em 1397, somente aos quarenta anos ele se apresenta como pintor. Recebia pequenas encomendas como a pintura da caixa do órgão ou do chão do altar da capela do Podestà.

Apenas duas obras da autoria de Squarcione são conhecidas. Uma é o políptico de Lazzara, ${ }^{1}$ pintado para essa família entre 1449 e 52, com um São Jerônimo no centro, atualmente no museu de Pádua. A outra, assinada, é a Nossa Senhora com o Menino. ${ }^{2}$ A dessemelhança de estilo faz supor que Squarcione recorresse ao trabalho dos alunos.

Em 1560, Bernardino Scardeone, autor de uma História de Pádua, escreveu a biografia de Squarcione. Sua fonte foram os relatos do próprio Squarcione, que se vangloriava de ser o primeiro pintor de seu tempo e o fundador da pintura humanista. Segundo ele, dedicara a infância à pintura e, ainda muito jovem, fora conhecer o mundo, formando uma coleção de desenhos e moedas antigas.

No entanto, no inventário feito após sua morte não aparecem os objetos raros e preciosos que ele teria trazido de Roma e da Grécia e que, ainda de acordo com Squarcione, seriam o fundamento da arte humanista. Na primeira metade do século XV em Pádua, todas as encomendas importantes eram confiadas a artistas de fora da cidade, o que também sugere não haver ali quem pudesse ser considerado um mestre.

O ateliê foi aberto no ano de 1431 e por lá passaram 137 alunos. O primeiro nome é o de Michele di Bartolomeo da Vicenza, que entrou como aprendiz do ateliê e empregado da casa. O mais provável é que fosse freqüentado por jovens em parte já conhecedores do ofício.

Independente do valor de Squarcione como pintor ou mestre, o seu ateliê foi fundamental para a difusão do Renascimento na Itália setentrional. Pode-se imaginar a efervescência de idéias entre os jovens. Havia visitas dos humanistas e professores da Universidade. Discussões a respeito de novas experiências em relação às iniciais e aos ornamentos de manuscritos que se inspiravam nas inscrições antigas. E principalmente o impacto causado pela presença de Donatello, que viveu em Pádua por dez anos, de 1443 a 53.

\footnotetext{
${ }^{1}$ Francesco Squarcione (1397-1468), Poliptico de Lazara, 1449-52, Museu Cívico, Pádua

${ }^{2}$ Francesco Squarcione (1397-1468), Madonna con Bambino, c. 1443, Berlim
} 
De todos os artistas que passaram pelo ateliê de Squarcione, o que mais se destacou foi Andrea Mantegna.

Aos 17 anos, ele já era autor de uma pala de altar da igreja de Santa Sofia, atualmente perdida, que muito impressionou os contemporâneos. Nesse mesmo ano, Mantegna entrou na justiça contra Squarcione. A ação foi julgada em janeiro de 1448.

Squarcione recorreu a fraudes durante o processo e valeu-se de um contrato para assegurar a cooperação de seu aluno. Mais tarde em 1456, esse acordo foi considerado sem apoio legal e anulado, por ser Mategna ainda menor de idade ao tempo em que fora firmado. Um documento dos arquivos do Estado de Veneza registra que: "o jovem Mantegna levou seu mestre Squarcione perante a corte de justiça e pediu a anulação do contrato que haviam concluído em 1448 ”.

Mantegna havia sido adotado por Squarcione com cerca de dez anos, tendo provavelmente perdido os pais muito cedo. Aparece nos registros da Confraria dos pintores de Pádua como Andrea figluolo de Meser Francesco Squarzon depentore.

Além de Mantegna, Squarcione também adotou Marco Zoppo (1432-78) e, no fim da vida, Giovanni di Vendramin. Zoppo, assim como Mantegna precisou recorrer à justiça para desligar-se do pai adotivo. Outros discípulos deixaram tempestuosamente o ateliê, como Giorgio Schiavone e Dario Treviso. Os filhos adotivos de Squarcione provavelmente nada recebiam pelo seu trabalho, como o comprova o contrato de adoção de Marco Zoppo, no qual ele se comprometeu a não exigir qualquer pagamento por suas pinturas.

Mantegna uniu-se à prestigiosa família de pintores de Veneza, os Bellini, casando-se em 1453 com Nicolosia, filha de Jacopo, rival e desafeto de Squarcione, o que os distanciou ainda mais.

Antes disso, em 1448, no mesmo ano do processo de Mantegna, Squarcione estabelecera um contrato com a viúva de Antonio degli Ovetari para a decoração da capela funerária da família na igreja dos Eremitani.

A igreja dominicana dos Eremitani foi construída a partir de 1276 no local onde já houvera outra igreja. A arquitetura é típica do Duecento, com a planta retangular alongada. A segunda capela à direita do altar-mór é a Ovetari. Tem cerca de $11 \mathrm{~m}$ de profundidade por quase $9 \mathrm{~m}$ de largura.

No testamento, de 5 de janeiro de 1443, Antonio degli Ovetari legou uma quantia de 700 ducados de ouro para que a capela fosse decorada após sua morte com cenas da vida de São Tiago e São Cristóvão. Ele era benfeitor da irmandade de Santa Maria dei Servi, que mantinha um abrigo para peregrinos a caminho de Roma em honra a esses santos. Não se sabe ao certo quando faleceu, mas a 16 de maio de 1448, a viúva Madonna Imperatrice firmava o contrato para que o trabalho fosse dividido entre Giovanni d'Alemagna e Antonio Vivarini (1440-76) e os alunos de Squarcione, Nicolò Pizzolo (1421-53) e Andrea Mantegna. Giovanni d'Alemagna e o cunhado Antonio Vivarini, representavam a tradição do Trecento, enquanto que Mantegna e Pizzolo eram a modernidade. Pizzolo fora assistente de Donatello, mencionado em 1446 na obra do altar do Santo. Em 1448, ele era considerado o artista local 
mais evoluído, com grande domínio da perspectiva. A convivência dos dois pintores, Pizzolo e Mantegna, ambos de temperamento forte e difícil, foi desastrosa. Chegaram a ponto de necessitar intervenção judicial para trabalhar no mesmo espaço: um não podia obstruir o trabalho do outro e Pizzolo era obrigado a remover o tapume que impedia a iluminação da parede que Mantegna afrescava.

Os afrescos deveriam ser terminados até dezembro de 1450, mas devido a uma série de acidentes os trabalhos prosseguiram por muito mais tempo. Giovanni d'Alemagna morreu em 1450 e Vivarini abandonou a capela no ano seguinte. Faltaram recursos no fim desse ano. E Pizzolo foi morto em 1453, quando retornava para casa após o trabalho. Como observou Vasari: “se ele apreciasse a pintura tanto quanto as armas, teria sido um excelente artista e talvez tivesse vivido muito mais".

Ansuino da Forlì, Bono da Ferrara e Giovanni da Camerino também trabalharam nos afrescos, mas quem realmente esteve à frente do programa de decoração foi Mantegna. Os trabalhos foram reiniciados em novembro de 1453 e provavelmente se encerraram em janeiro de 1457.

Os afrescos da capela Ovetari foram quase completamente destruídos pelo bombardeio inglês de 11 de março de 1944, o que complica ainda mais o problema da atribuição e cronologia das obras, de que restam apenas fotos anteriores à Segunda Grande Guerra. Somente se salvaram dois episódios da História de São Cristóvão, que devido à má conservação haviam sido retirados para restauro em 1865 [Fig.1] ${ }^{3}$ e a Assunção da Virgem, no nicho da abside [Fig.2]. ${ }^{4}$

Mas o resultado não agradou à cliente.

Em meados de fevereiro do ano de 1457, na cidade de Pádua, foi levada a julgamento a ação que opunha a viúva Madonna Imperatrice Ovetari e Andrea Mantegna. O motivo da queixa contra o pintor era o número de figuras representadas na Assunção, apenas oito dos Apóstolos, enquanto a comitente esperava a presença de todos os doze.

O afresco encontra-se muito deteriorado. Existe uma cópia da Assunção, a gravura de Fancesco Novelli feita por volta de 1865 a partir de desenho de Luca Brida.

Para examinar e avaliar a obra foram designados os pintores Pietro da Milano, Giovanni Storlato da Venezia e o Francesco Squarcione.

Interrogado a 14 de fevereiro, Pietro da Milano declarou que devido às exíguas dimensões do espaço não teria sido possível representar todos os Apóstolos de corpo inteiro, mas talvez acrescentar as cabeças dos que faltavam, se bem que com prejuízo da perspectiva. No entanto, a qualidade da pintura era tal, que pelas oito figuras, Mantegna merecia receber tanto quanto se fossem doze. Giovanni Storlato, depondo no dia seguinte, considerou que os doze Apóstolos poderiam ter sido pintados de tamanho menor.

\footnotetext{
3 Andrea Mantegna, Martírio e Translado do corpo de São Cristóvão, 1452, base:330 cm, capela Ovetari, igreja Eremitani, Pádua

${ }^{4}$ Andrea Mantegna, Assunção da Virgem,c.1456, capela Ovetari, igreja Eremitani, Pádua
} 
A apreciação de Squarcione foi cáustica. Como relata Vasari:

(...) (Squarcione ) condenou sem qualquer respeito as pinturas que Andrea fizera na citada capela de São Cristóvão, dizendo que não eram coisa boa porque havia ao fazê-las imitado as coisas de mármore antigas, a partir das quais não se pode aprender a pintura perfeitamente, já que as pedras têm sempre a rigidez que lhes é própria e jamais a tenra maciez que têm a carnação e as coisas naturais que se dobram e fazem diversos movimentos, acrescentando que Andrea teria feito muito melhor aquelas figuras e que teriam ficado mais perfeitas se as houvesse feito da cor do mármore e não de tantas cores, já que as pinturas não se assemelhavam aos vivos mas a estátuas antigas de mármore e de outras coisas similares.

Não deixa de ser curioso que Squarcione criticasse em Mantegna justamente o que ele se vangloriava de ensinar aos discípulos: a cópia de esculturas antigas.

De acordo com Vasari, a reação de Mantegna às críticas de Squarcione foi o que o conduziu à pintura de retratos:

Uma tal repreensão ofendeu o ânimo de Andrea, mas, por outro lado, lhe foi de muito proveito, porque reconhecendo que ele em grande parte dizia a verdade, pôsse a retratar pessoas vivas e fez nisso tanto progresso, que em uma história que na dita capela lhe restava fazer, mostrou que sabia não menos extrair o que é bom das coisas vivas e naturais, que daquelas feitas a partir da arte. (...).

Os retratos nas paredes da capela Ovetari eram de humanistas e literatos de Pádua que compunham o círculo de amigos, e por vezes patronos, de Andrea Mantegna.

Antes da publicação da Giuntina, Vasari viajou para o norte. Ele identificou os contemporâneos que Mantegna retratou em meio aos santos na cena do Martírio de São Tiago. Nem todos se encontram ali.

De acordo com Vasari, nos afrescos da Ovetari foram retratados:

Noferi di Messer Palla Strozzi florentino, Messer Girolamo dalla Valle, médico excelentíssimo, Messer Bonifazio Fuzimeliga, doutor de leis, Niccolò, ourives do Papa Inocêncio VIII, e Baldassare da Leccio, amicíssimos seus. Todos os quais representou vestidos com armaduras brancas brilhantes e esplêndidas, como o são realmente, e decerto com a bela maneira.

É mais provável que se encontrem entre os personagens do Martírio e Translado do corpo de São Cristóvão.

Noferi di Messer Palla Strozzi era filho do florentino Palla Strozzi, exilado em Pádua desde 1434 devido a divergências com os Medici. Sua presença foi da maior importância para a cultura da cidade. Colecionava manuscritos antigos e contratava tradutores gregos. Era muito estimado e respeitado e viveu em Pádua até sua morte em 1462. Como em Florença, devotou-se ao estudo do latim e do grego e o seu studio atraiu um círculo de eruditos. Muito provavelmente foi por seu intermédio que Donatello foi chamado a trabalhar na igreja do Santo.

Continuando com a listagem dos personagens, escreve Vasari:

Retratou ainda Messer Bonramino, cavalheiro, e um certo bispo da Hungria, homem totalmente perturbado, o qual andava o dia todo por Roma como um 
vagabundo e depois, à noite, se contentava em dormir pelos estábulos com os animais.

O bispo húngaro é tradicionalmente identificado como o humanista e poeta Janus Pannonius (c.1431-após 1465), bispo de Pecs. Era um grande colecionador de textos gregos e latinos e fora aluno de Guarino da Verona no studio de Ferrara. Mantegna retratou-o juntamente com o humanista e professor da Universidade de Pádua Galeotto Marzio (c.1424-c.1497) em um retrato duplo de inspiração ciceroniana que celebrava a amizade. A obra foi pintada por volta de 1455, muito provavelmente em Pádua, onde se encontravam os três amigos. Eram ainda jovens, Pannonius contava por volta de vinte e quatro anos e Marzio, trinta e um. O retrato duplo é conhecido unicamente através do poema que Pannonius dedicou a Mantegna por volta de 1458 depois de ter retornado à Hungria. Enaltece a semelhança dos retratos e a qualidade do pintor: De acordo com Burckhardt: $:^{5}$ "o retrato dos dois humanistas talvez tenha sido o primeiro exemplo de união, não de sangue ou função oficial, mas de estudo e amizade”.

A descrição que Vasari faz de Pannonius não corresponde à do livreiro florentino Vespasiano da Bistici, que o conheceu pessoalmente. Para Vespasiano, Pannonius: "era um jovem de belíssima presença e de maravilhosos costumes que por suas muitas virtudes provocava admiração em Ferrara, sendo livre de qualquer vício e portador de todas as virtudes, não havendo estrangeiro ou italiano da mesma idade que a ele se equiparasse". Pannonius encantou a todos com quem conviveu durante a estadia em Florença, antes de retornar à Hungria a chamado do tio, o arcebispo de Strigonia.

O homem totalmente perturbado de que fala Vasari talvez seja Marsilio Pazzo, por mera sugestão do nome. É o único personagem que pode ser efetivamente identificado como o carrasco que decepa a cabeça de São Tiago.

Acompanhando a descrição de Vasari: “nesta última história, a qual agradou infinitamente, Andrea retratou Squarcione como uma figura roliça com lança e espada na mão". Pode ser visto também na cópia feita por um contemporâneo. O retrato provavelmente não agradou ao modelo.

Vasari termina o relato sobre a capela contando que Mantegna "retratou igualmente a si mesmo. Em suma, esta obra lhe conquistou pela sua bondade nome grandíssimo".

O auto-retrato talvez seja a cabeça gigantesca à esquerda no arco, à qual deveria corresponder a de Pizzolo no outro extremo.

Os afrescos da vizinha capela Scrovegni pintada por Giotto nos primeiros anos do Trecento, especialmente as figuras dos Vícios e das Virtudes, exerceram forte influência sobre o trabalho inicial de Mantegna. O próprio local da igreja dos Eremitani, a antiga Arena de Pádua, deve ter sido inspirador para o artista apaixonado pela Antiguidade.

O fato do amadurecimento artístico de Mantegna ter sido precoce permitiu que na metade do século, quando ainda vivia em Pádua, influência já se refletisse em toda a Itália setentrional. Os retratos da capela Ovetari foram a sua afirmação como artista.

${ }^{5}$ BURCKHARDT, JACOB, Il ritratto nella pittura italiana del Renascimento, p. 108 


\section{Referências bibliográficas}

VASARI, GIORGIO- Le Vite de'più eccellenti pittori, scultori ed architettori nelle redazione del 1550 e 1568, Ed. Paola Barocchi e Rossana Bettarini, Florença, 1987

BURCKHARDT, JACOB, L'arte italiana del Rinascimento, Marsilio, Veneza, 1995

ROMANO, G., Storia dell'arte italiana: da Mantegna a Raffaello, vol. 1l, Einaudi, Milão, 1976

VENTURI, A., Storia dell'arte Italiana, vol. Vll, La pittura del Quattrocento, Einaudi, Primeira ed. 1914, , Kraus-Thomson reprint, N. York, 1983

BELLONCI, MARIA e GARAVAGLIA, NINY, Mantegna, Rizzoli, Milão, 1966

BOCCAZZI, F., Mantegna, Thames and Hudson, Londres, 1971

CAMESASCA, ETTORE, Mantegna, Scala, Florença, 1992

CIERI VIA, CLAUDIA, Mantegna, Giunti, Florença, 1996

KRISTELLER, P., Andrea Mantegna, Longmans, Londres, 1901

LIGHTBOWN, RONALD, Mantegna, Mondadori, Milão, 1986

MARTINEAU, J. (coord.), Catalogue Andrea Mantegna, Electa Milão, 1992 